
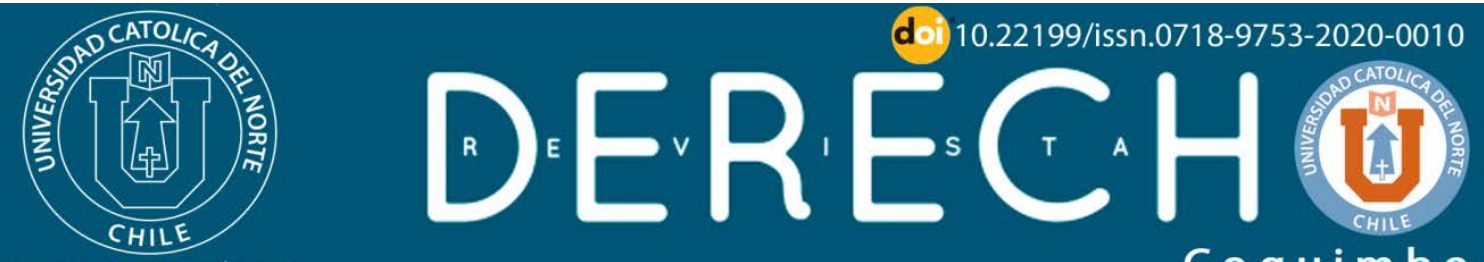

REVISTAS CIENTÍFICAS
de la Universidad Católica del Nortc.

C O q u i m b o

ISSN: 0718-9753 (En línea)

\title{
Los acuerdos extrajudiciales en materia de libre competencia como tutela cautelar autónoma
}

\section{Extrajudicial solutions in the field of competition rules as autono- mus ways injusticion}

\author{
Alejandro Romero Seguel ${ }^{1}$ (D) https://orcid.org/0000-0002-4234-1182 \\ 'Universidad de Los Andes, Santiago, Chile. Profesor de Derecho Procesal. Doctor en Derecho, U. de- \\ Navarra, España.

\section{Resumen:}

Se analizan los acuerdos extrajudiciales que suscribe la Fiscalía Nacional Económica con agentes del mercado y cuya aprobación debe dar el Tribunal de Defensa de la Libre Competencia. El objetivo de la investigación es demostrar la naturaleza cautelar autónoma que tiene este instrumento. Al ser concebidos de esa forma se explica de mejor forma una serie de problemas que surgen después de que el Tribunal de Defensa de la Libre Competencia le da su aprobación "sin forma de juicio", esto es, sin emitir un pronunciamiento sobre el fondo de una acción deducida. Al tratarse de medidas provisionales, su contenido se puede cambiar acudiendo al tribunal que las aprobó.

Palabras Clave: Medidas precautorias; Proceso cautelar autónomo; Acción procesal.

\begin{abstract}
:
Extrajudicial settlement between the $\mathrm{Na}$ tional Economic Prosecutor and market agents are analyzed. These settlements must be approved by the Court of Defence of Free Competition. The objective of this article is to demonstrate the nature of this mechanism to protect the free competition. This mech considered the elements that characterize this form of protection, especially, that there is no pronouncement on the substance of public law that consists of the action. As these are provisional measures, their content can be changed by going to the court that approved them anism is a manifestation of protective guardianship, and therefore all its effects must be.

Keywords: Precautionary measures; Autonomous precautionary process; Free competition.
\end{abstract}


Los acuerdos extrajudiciales en materia de libre competencia como tutela...

\section{Introducción}

Un tema jurídico de interés, son los efectos de los denominados acuerdos extrajudiciales que suscribe la Fiscalía Nacional Económica con agentes del mercado y cuya aprobación debe dar el Tribunal de Defensa de la Libre Competencia (Sobre este tema; Valdés Prieto, 2011; Rivas Sánchez , 2018; y Arancibia Mattar, 2013). Tal como se intentará demostrar, este singular acto procesal es una manifestación de la tutela cautelar contemplada dentro del mecanismo de protección jurídica que delimita el art. 1 del Decreto Ley $N^{\circ} 211$ (1973), al señalar que esa normativa tiene por objeto promover y defender la libre competencia en los mercados. Y de manera específica, al indicar que, "Ios atentados contra la libre competencia en las actividades económicas serán corregidos, prohibidos o reprimidos en la forma y con las sanciones previstas en esta ley" (Decreto con Fuerza Ley $\mathrm{N}^{\circ} 1,2005$, art. 1).

Los acuerdos extrajudiciales, son uno de los varios correctivos existentes para proteger anticipadamente la libre competencia. A través de su celebración, se cumple el objetivo general que la Corte Suprema asigna a esta normativa, cuando señala que:

...la finalidad de la legislación antimonopolio, comprende el resguardo de la independencia y autonomía de los agentes mercantiles, sean ellos productores, comerciantes o consumidores, con el propósito de asegurar o fomentar los procesos competitivos efectivos, promover el bienestar del público consumidor, aumentar los niveles de eficiencia, proteger la equidad, la igualdad y la integración de los mercados, cautelando el ejercicio lícito de la autonomía privada en un mercado imperfecto. (Etcom S. A. con Telefónica Móviles Chile S.A, 2017, cons. 10).

De un modo específico, los acuerdos extrajudiciales forman parte de la cautela autónoma que admite el art. 3 del Decreto Ley $N^{\circ} 211$ (1973), cuando dispone que para evitar que se ejecuten o celebren, individual o colectivamente cualquier hecho, acto o convención que impida, restrinja o entorpezca la libre competencia, o que tienda a producir dichos efectos, junto a las sanciones, también se pueden adoptar "las medidas preventivas, correctivas o prohibitivas que respecto de dichos hechos, actos o convenciones puedan disponerse en cada caso" (Decreto con Fuerza Ley N 1, 2005, art. 3).

Al ser concebidos los acuerdos extrajudiciales como una manifestación cautelar autónoma, se explica de mejor forma una serie de problemas que surgen después de que el Tribunal de Defensa de la Libre Competencia le da su aprobación "sin forma de juicio", dentro de las varias posibilidades que existen para organizar la protección de la libre competencia, una explicación de los posibles diseños institucionales 
para la protección de la libre competencia, puede encontrarse en Romero Guzmán (2014).

Estos acuerdos, se originan en una negociación entre la Fiscalía Nacional Económica y los actores investigados por eventuales conductas contra la libre competencia. Una vez acordado su contenido, se someten al conocimiento del Tribunal de Defensa de la Libre Competencia, mediante una presentación que contiene un informe de la Fiscalía Nacional Económica, con una descripción de la investigación realizada y la descripción del mercado relevante involucrado en el acuerdo y las medidas de mitigación cuya aprobación solicitan. En ese mismo acto, la Fiscalía Nacional Económica consigna si investigó los hechos de oficio o mediante una denuncia de terceros; en este último caso, deja constancia que realizó un examen de admisibilidad de la denuncia, con el propósito de determinar si existían antecedentes suficientes que justificaran iniciar una investigación conforme a las facultades del art. 39 letra a) del DL Nº 211 (1973) (Valdés Prieto, 2006, pp. 704-707).

Desde el punto de vista normativo, los acuerdos extrajudiciales están reconocidos en el art. 39 letra ñ) del DL № 211 (1973), al facultar al Fiscal Nacional Económico para:

ñ) Suscribir acuerdos extrajudiciales con los agentes económicos involucrados en sus investigaciones, con el objeto de cautelar la libre competencia en los mercados.

El Tribunal tomará conocimiento del acuerdo en una sola audiencia, sin forma de juicio, convocada especialmente al efecto, dentro del quinto día hábil de recibidos los antecedentes, durante la cual podrá escuchar alegatos de las partes comparecientes al acuerdo, así como el parecer de quienes tengan interés legítimo. Se presumirá que tienen interés legítimo el Servicio Nacional del Consumidor y las asociaciones de consumidores establecidas en la ley $N^{\circ} 19.496$. El Tribunal deberá aprobar o rechazar el acuerdo en un plazo máximo de quince días hábiles, contados desde la fecha de la audiencia. Estas resoluciones una vez ejecutoriadas serán vinculantes para las partes que comparecieron al acuerdo y en su contra sólo procederá el recurso de reposición. (Decreto con Fuerza Ley N 1, 2005, art. 39, ñ)

Ha sido una constante en la jurisprudencia, que el Tribunal de Defensa de la Libre Competencia les preste su aprobación, pero previniendo que lo hace sin contar con información suficiente para pronunciarse definitivamente sobre las medidas mitigatorias propuestas, agregando que, en ese acto, no cuenta con mayores razones para rechazar el mentado acuerdo, asumiendo que su contenido permitirá mejorar las condiciones competitivas del mercado. A modo de referencia:

Decimocuarto: Que atendido el breve plazo establecido por la ley para aprobar o rechazar un acuerdo extrajudicial, el estudio del Acuerdo Extrajudicial por parte de este Tribunal tiene por objeto comprobar si la investigación y 
análisis realizados por la FNE que le sirvieron de fundamento, cumplieron con los parámetros y exigencias propios para la evaluación de una operación de concentración.

Decimoquinto: Que, en este sentido, no existen en el proceso antecedentes ni argumentos que permitan desvirtuar el análisis económico realizado por la FNE;

Decimosexto: Que, asimismo, el análisis de los riesgos para la libre competencia que la FNE detectó en su investigación parece correcto, atendidas las características de los mercados concernidos, el nivel de competencia y las condiciones de entrada que analizó la Fiscalía en su investigación.

Decimoséptimo: Que lo mismo puede señalarse respecto de las medidas de mitigación propuestas en el Acuerdo Extrajudicial para evitar que se reduzca sustancialmente la competencia en los mercados afectados por la Operación .... (Acuerdo Extrajudicial entre FNE y Holchile S.A. e Inversiones Caburga Ltda, 2017).

Esa modalidad de aceptación, no hace más que ratificar que estamos frente a un acto de naturaleza cautelar, por las razones que se pasan a explicar.

\section{La tutela diferenciada del derecho en el proceso de libre compe- tencia}

Una tendencia jurídica que en el último tiempo ha tenido un interesante desarrollo en el ámbito procesal, es la denominada como la tutela diferenciada del derecho. Se trata de un fenómeno que se caracteriza por la implementación de diferentes instrumentos jurídicos para solucionar conflictos sin seguir, rigurosamente, los moldes clásicos de los procesos declarativos o de ejecución (Una descripción del tema en, Proto Pisani, 2014, pp. 189-382) ${ }^{1}$. A través de la tutela diferenciada, se pueden adoptar medidas para satisfacer o proteger anticipadamente el derecho.

Dicho de otra forma, se trata de diversas propuestas técnicas que intentan convertirse en alternativas a la estructura clásica del proceso civil, que supedita el modelo de solución de conflictos al ejercicio de una acción en un procedimiento contencioso, cuya decisión queda reservada al pronunciamiento de la sentencia definitiva. La concreción de esta modalidad se aprecia en el desarrollo de diversos instrumentos, tales como las medidas autosatifactivas, las sentencias anticipatorias, la tutela preventiva, los procesos cautelares autónomos, por citar las opciones más recurrentes.

En nuestra legislación, una de las manifestaciones de la tutela diferenciada ha surgido en materia de libre competencia, al reconocer la posibilidad de suscribir acuerdos extrajudiciales entre la Fiscalía Nacional Económica y los agentes económicos involucrados en una investigación administrativa.

\footnotetext{
${ }^{1}$ Además entre la abundante bibliografía, sobre el contenido de estos mecanismos, Berizonce (2009, pp. 15-150); Pérez Ragone (2000); Aguirrezabal Grünstein (2013); Aguirrezabal Grünstein (2016).
} 
Este aporte se introdujo en la Ley № 20.361 de 2009, al permitir una forma de protección al funcionamiento del mercado, combinando potestades administrativas y jurisdiccionales. Entre otros antecedentes, la entidad del cambio fue consignada en la Historia de la Ley por los representantes del Poder Ejecutivo ante la Cámara de Diputados, al indicar que con este instrumento “...pretendía desjudializar algunos casos de competencia, es decir, permitir llegar a acuerdos extrajudiciales en términos similares a las soluciones alternativas a que puede llegar el Ministerio Público, contando siempre con autorización del Tribunal" (Historia de la Ley 20.361, 2018, p. 104)2. De igual forma, ilustra este giro las palabras consignadas en el debate parlamentario cuando se puntualiza que,

Es efectivo, también, lo señalado por el Senador señor Ominami en el sentido de que los acuerdos extrajudiciales han contribuido muchísimo a mejorar la libre competencia sin tener que llegar a procedimientos de carácter contencioso. Creo que se debe facilitar ese sistema en mayor medida que la consignada en el texto aprobado por la Cámara de Diputados" (Historia de la Ley $20.361,2018$, p. 180$)^{3}$

\section{La naturaleza cautelar de los acuerdos extrajudiciales}

Sin perjuicio de otros elementos de interpretación, la clave para determinar la naturaleza jurídica que se debe atribuir a estos acuerdos se aprecia en el objeto a que tiende su celebración; según el art. 39 letra ñ) del Decreto Ley № 211 de 1973, estos acuerdos deben suscribirse para "...cautelar la libre competencia en los mercados" (Decreto con Fuerza Ley $N^{\circ} 1,2005$, art. 39, ñ).

Ahora, como lo indica el Código Civil (2000), "Las palabras de la ley se entenderán en su sentido natural y obvio, según el uso general de las mismas palabras..." (art. 20). De igual forma, el art. 21 del mismo cuerpo legal indica que "Las palabras técnicas de toda ciencia o arte se tomaran en el sentido que les den los que profesan la misma ciencia o arte; a menos que aparezca que claramente se han tomado en sentido diverso" (Código Civil, 2000, art. 21).

Al tratarse explícitamente de una manifestación de la tutela cautelar, todos sus efectos se deben analizar considerando los elementos propios de esta forma de protección jurídica. Como se sabe, a través de la protección cautelar se logra una forma de amparo diversa de la que resulta del ejercicio de una acción. En efecto, conforme a la jurisprudencia de la Corte Suprema, de 31 de agosto de 2011:

Ante el ejercicio de una acción, que en el orden de los principios, es un derecho subjetivo autónomo dirigido a obtener una determinada resolución ju-

\footnotetext{
${ }^{2}$ Informe de Comisión de Constitución en Sesión 84, Legislatura 355, Primer Trámite Constitucional. Fecha 13 de septiembre de 2007.

${ }^{3}$ Sesión 85. Legislatura 355. Discusión General. Segundo Trámite Constitucional: Senado. Fecha 22 de enero, 2008.
} 
Los acuerdos extrajudiciales en materia de libre competencia como tutela...

risdiccional, favorable a la petición del reclamante, cabe distinguir las condiciones para el ejercicio de la acción y aquellas requeridas para obtener una sentencia favorable. La ausencia de alguna de las condiciones de fondo, determinará el rechazo de la demanda en la sentencia; pero, entretanto, la acción se habrá ejercitado y producido sus efectos dentro del proceso. (Órbenes Órbenes, Sergio y otro con Meza Tapia, Enrique, 2011, cons. 13)

Nuestra jurisprudencia, en relación al ejercicio de la acción, distingue entre acciones de condena, constitutivas y de declaración de certeza. Entre otras, así lo revela la sentencia de la Corte Suprema, de 26 de marzo de 2018, al señalar:

Que, al respecto, debe recordarse que, conforme enseña la doctrina procesal, las acciones declarativas son aquellas cuyo objeto es resolver situaciones de —'incertidumbre jurídica', donde el juzgador debe dilucidar la determinada naturaleza de una situación existente, o, simplemente descartarla, en otras palabras 'la constatación judicial de la existencia o inexistencia de una relación o situación jurídica' (...), mientras que la acción es constitutiva cuanto su objeto sea la 'creación de un estado jurídico que antes no existía; proporcionar a una obligación ya existente el complemento integrador que necesita, haciéndola exigible; producir un cambio de estado jurídico existente; cancelar o dejar sin efecto un estado jurídico preexistente'(...). De este modo, en las sentencias declarativas 'sus efectos se remontan al pasado', y en las constitutivas, se extienden hacia el futuro (como afirma Hugo Alsina, conforme señala en Fundamentos del Derecho Procesal, Editorial Jurídica Universitaria, México, 2001, p. 133). (Bustamante con Román, 2018, cons. 7)

Tampoco en este caso se trata de una acción de cesación, que se caracteriza por la deducción de una pretensión que busca obtener un "dejar de hacer" o una prohibición de realizar alguna actividad en el presente o futuro, mediante el pronunciamiento de una sentencia en tal sentido (Sobre el tema: Ariza Colmenarejo, 2012, pp. 11-16). La Corte Suprema acepta expresamente esta diversidad en la protección del derecho, señalando que en materia de protección al consumidor,

Conforme al objetivo, las acciones pueden ser agrupadas en punitivas o sancionatorias, reparatorias y de cesación. Las primeras persiguen hacer efectiva la responsabilidad contravencional o infraccional a través de una sanción impuesta al autor de la conducta que la ley castiga. Con las segundas se pretende la reparación de los perjuicios (materiales y morales) causados a los consumidores por la conducta del proveedor; a este respecto la ley también contempla el ejercicio de otras acciones civiles, distintas a las indemnizatorias, que incluso pueden complementarlas, como las que persiguen la declaración de nulidad de las cláusulas abusivas incorporadas en los contratos de adhesión o el cumplimiento de la obligación incumplida. Y las terceras pretenden la declaración del cese o abstención de las actividades o conductas estimadas ilícitas; se aspira así que junto con la paralización de la actuación sea evitada su repetición en el futuro, constituyendo un conveniente medio de tutela preventiva. Tienen por objeto, como lo indica un autor, 'el cese de una actividad o de una conducta ilí- 
cita potencialmente dañosa de los derechos e intereses legítimos de los consumidores y usuarios, impidiendo su reiteración en el futuro al condenar al empresario o profesional demandado a abstenerse de realizar o de reiterar el comportamiento lesivo de los referidos derechos e intereses legítimos en el futuro'. (Busto Lago, citado por Gonzalo Cortez, en "Comentarios a la Ley de Protección a los Derechos del Consumidor". Edit. Legalpublishing. Santiago, 2014, págs. 959 y 960). (Servicio Nacional del Consumidor con Ticketmaster Chile S.A, 2018 cons. 6$)$

En el caso de la regulación de los acuerdos extrajudiciales, la protección de los derechos se explica por el ejercicio de la potestad administrativa prevista para el Fiscal Nacional Económico en el art. 39 letra ñ), que constituye una actuación distinta de la deducción del derecho de acción, que evita iniciar un largo y costoso juicio (Sobre los costos de estos juicios, ver; Pardow, 2015). Esto se aprecia, entre otras razones, al comparar esta forma de actuación con las prerrogativas que le conceden las letras b) y c) del mismo precepto legal. En la de la letra ñ), la misma norma indica que el Tribunal de Defensa de la Libre Competencia debe conocer de ese asunto, "sin forma de juicio", lo que es equivalente a señalar que no conoce del derecho público subjetivo en que consiste la acción. Como bien lo indica Arancibia Mattar (2013), "...en el orden administrativo, el acuerdo es una potestad discrecional conferida por la ley a la Fiscalía Nacional Económica para la defensa del interés general de la colectividad en la libre competencia" (p. 480).

De manera puntual, los acuerdos extrajudiciales son una manifestación de la tutela cautelar jurisdiccional, atendido que son conocidos y aprobados por el Tribunal de Defensa de la Libre Competencia. En tal sentido, es importante destacar la naturaleza jurisdiccional de la protección cautelar, atendido que en el plano teórico existen situaciones en las que es complejo deslindar entre la actividad jurisdiccional y la administrativa, por existir zonas grises que dificultan esta separación (Un estudio de este tema en: Velozo Alcaide y González Delpiano, 2011). En el caso de las medidas de protección cautelar, ellas no son privativas de la función jurisdiccional, como se aprecia, por ejemplo, en la ley de procedimiento administrativo № 19.880, de 29 de mayo de 2003, cuando reconoce en el art. 32, la posibilidad que la administración pueda adoptar "medidas provisionales". En este caso, por las razones que se pasan a explicar, la tutela cautelar es de naturaleza jurisdiccional.

En la doctrina Valdés Prieto (2010) le da otra calificación, sosteniendo que:

La actividad contralora que realiza el TDLC respecto del acuerdo extrajudicial no pertenece al orden jurisdiccional (aunque sí al judicial), puesto que si se tratase de ejercicio de jurisdicción dicho acuerdo jamás podría ser caracterizado como equivalente jurisdiccional. Así, la naturaleza de esta actividad contralora es de orden no contencioso. La actividad de control que ha de efectuar el TDLC reviste un carácter específico y concreto y resulta necesaria 
Los acuerdos extrajudiciales en materia de libre competencia como tutela...

para que un acuerdo extrajudicial surta toda su eficacia y, por ello, debemos calificar este acuerdo extrajudicial como solemne. (p. 230)

\section{La protección cautelar y los acuerdos extrajudiciales}

El desarrollo dogmático de la tutela cautelar, ha sido un tema de permanente debate y desarrollo doctrinal, legal y jurisprudencial ${ }^{4}$.

La tutela cautelar, desde una perspectiva general, comprende todas las medidas que tienden a asegurar la eficacia de un derecho, considerando desde las medidas de aseguramiento y conservación de la prueba, hasta las clásicas manifestaciones de las medidas precautorias conservativas o innovativas que la ley admita dictar o adoptar en los distintos tipos de procesos.

Dentro de las múltiples discusiones que genera esta materia, uno de interés para el tema en estudio, es determinar si la protección cautelar puede configurar una manifestación autónoma y distinta de las clásicas formas de protección que el proceso concede mediante la actuación de la tutela declarativa o ejecutiva (Una síntesis del tema en: Ramos Romeu, 2006).

En la Ley $N^{\circ} 1.552$ (1902), el sistema cautelar está conformado como un mecanismo accesorio al ejercicio del derecho de acción, y señala que, "Para asegurar el resultado de la acción, puede el demandante en cualquier estado del juicio, aun cuando no esté contestada la demanda, pedir una o más de las siguientes medidas..." (art. 290). La misma solución se aprecia en las medidas prejudiciales precautorias, que imponen el deber de presentar la demanda dentro del término legal, bajo sanción de caducidad (Ley $N^{\circ} 1.552,1902$, art. 280).

En cambio, en la regulación de los acuerdos extrajudiciales la protección cautelar reconoce expresamente un rasgo de autonomía que lo diferencia del sistema general. No compartimos la calificación que se ha hecho de estos acuerdos con los instrumentos que rigen en el proceso penal como una medida alternativa a la pena. En tal sentido, se ha señalado que,

...la suscripción de acuerdos extrajudiciales se basa en una facultad entregada a la FNE con ocasión de la reforma efectuada a la Ley de Defensa de la Libre Competencia (DL 211) en el año 2009, mediante la Ley No 20.361, que incorporó el actual 39 letra ñ). Sin embargo, resulta dudoso que los acuerdos extrajudiciales hayan sido creados para solucionar asuntos de alta complejidad e impacto como el que recayó en el mercado del litio. Si se revisa la historia de dicha ley queda en evidencia el hecho de que los acuerdos extrajudiciales no fueron concebidos como un procedimiento de aplicación general para

\footnotetext{
${ }^{4}$ Entre la abundante bibliografía, con las tendencias producidas en el derecho comparado, Carrasco Delgado (2012); Marín González (2016); Bordalí Salamanca (2001); Rojas, J. A. (2006); Proto Pisani (2014); Romero Seguel (2017).
} 
asuntos complejos o de alta gravedad, sino más bien como una especie de salida alternativa para casos de baja lesividad contra el bien jurídico que se protege y que —en virtud del Principio de Oportunidad - pueden resolverse sin necesidad de incoar los procedimientos de lato conocimiento que el DL 211 establece como de aplicación general (contencioso o no contencioso). (Reyes Cid, 2018)

Este elemento distintivo y original, demuestra que se ha incorporado a nuestro sistema un instrumento que para lograr la protección cautelar no requiere ni impone que se ejerza una acción, que genere la necesidad de tramitar un proceso que culmine con una sentencia que sobre el fondo, como se desprende de la definición legal de la sentencia definitiva en el art. 158 de la Ley $N^{\circ} 1.552$ (1902).

Lo anterior, se ve ratificado por el contenido que el Tribunal de Defensa de la Libre Competencia les asigna cuando aprueba las medidas tendientes a modelar e imponer determinadas conductas, para facilitar la libre concurrencia de los agentes de mercado. Por regla general estas resoluciones no imponen sanciones, sino que aprueban actuaciones positivas o negativas, que los agentes del mercado investigados deben cumplir como parte del acuerdo. Una excepción se encuentra en el Acuerdo extrajudicial entre la FNE e International Mainstream Renewable Power Limited (2018), que informó fuera de plazo su participación minoritaria en una firma con la cual compite. En ese caso se le impuso el pago de 33,5 Unidades Tributarias Anuales (UTA). Dicho acuerdo fue aprobado por el Tribunal de Defensa de la Libre Competencia el 24 de mayo de 2018.

A modo de ejemplo, lo que se viene indicando consta en una serie de resoluciones que pasamos a reseñar.

En los autos del Tribunal de Defensa de la Libre Competencia, Rol AE No 142017, con fecha 29 junio 2017 se aprobó el acuerdo extrajudicial alcanzado entre la Fiscalía Nacional Económica, y Holchile S.A. e Inversiones Caburga Limitada. Para el tema que interesa ilustrar allí se señala:

Decimocuarto: Que atendido el breve plazo establecido por la ley para aprobar o rechazar un acuerdo extrajudicial, el estudio del Acuerdo Extrajudicial por parte de este Tribunal tiene por objeto comprobar si la investigación y análisis realizados por la FNE que le sirvieron de fundamento, cumplieron con los parámetros y exigencias propios para la evaluación de una operación de concentración.

Decimoquinto: Que, en este sentido, no existen en el proceso antecedentes ni argumentos que permitan desvirtuar el análisis económico realizado por la FNE;

Decimosexto: Que, asimismo, el análisis de los riesgos para la libre competencia que la FNE detectó en su investigación parece correcto, atendidas las características de los mercados concernidos, el nivel de 
Los acuerdos extrajudiciales en materia de libre competencia como tutela...

competencia y las condiciones de entrada que analizó la Fiscalía en su investigación.

Decimoséptimo: Que lo mismo puede señalarse respecto de las medidas de mitigación propuestas en el Acuerdo Extrajudicial para evitar que se reduzca sustancialmente la competencia en los mercados afectados por la Operación... (Acuerdo Extrajudicial entre FNE y Holchile S.A. e Inversiones Caburga Ltda., 2017)

En los autos del Tribunal de Defensa de la Libre Competencia, Rol AE № 122015, de 16 de septiembre de 2015, se establece:

Vigésimo: Que, sin perjuicio de las restricciones referidas en la consideración anterior, este Tribunal coincide prima facie con el análisis efectuado por la Fiscalía Nacional Económica respecto de los mercados relevantes en los que incidiría la Operación y con la existencia de eventuales riesgos derivados de la adquisición por Electrolux de un interés minoritario activo en Mabe. Asimismo, concuerda con la Fiscalía respecto de la necesidad de adoptar medidas tendientes a mitigar tales riesgos; (...)

Vigésimo sexto: Que, en definitiva, este Tribunal aprobará el acuerdo extrajudicial entre la Fiscalía Nacional Económica y Electrolux Chile, pues las medidas conductuales contenidas en él permiten mitigar razonablemente los riesgos para la libre competencia identificados en la investigación Rol No F38-2014; y,

Vigésimo séptimo: Que la aprobación de este acuerdo extrajudicial sólo implica un pronunciamiento sobre los hechos a que él se refiere, en especial sobre las medidas de mitigación acordadas, y no impide que terceros que pudieren verse afectados por eventuales infracciones a la libre competencia puedan presentar las acciones que en su concepto procedan. (Acuerdo extrajudicial entre FNE y Electrolux Chile S.A., 2015).

También revela lo que se intenta explicar, lo decidido en los autos del Tribunal de Defensa de la Libre Competencia, Rol AE No 10-2014, de 6 de noviembre de 2014, cuando declaró:

Decimo: Que, atendido el breve plazo establecido por la ley para aprobar o rechazar un acuerdo extrajudicial y la inexistencia de una etapa procesal que permita recabar más antecedentes que los contenidos en el expediente de investigación de la FNE, es difícil para este Tribunal efectuar un análisis acabado del o de los mercados relevantes y de los efectos para la libre competencia de una operación de concentración como la de autos, y más aún establecer cuáles son las medidas más adecuadas para mitigar o compensar debidamente los riesgos asociados a ella. Por este motivo, el análisis se limitará a establecer si las medidas acordadas por la Fiscalía con Oben Group son suficientes para prevenir eventuales riesgos para la libre competencia. (Acuerdo Extrajudicial entre Fiscalía Nacional Económica, Oben Holding Group S.A.C, Bopp Chile S.A. y Pack Film Chile SpA., 2014)

Luego, es interesante del mismo fallo lo señalado en los siguientes conside- 
randos:

Decimocuarto: Que respecto de las demás medidas, este Tribunal estima que ellas también resultan razonables para prevenir eventuales efectos para la competencia derivados de la operación de concentración objeto del acuerdo;

Decimoquinto: Que por lo anterior, este Tribunal aprobará el acuerdo, atendido que, como se dijo, las medidas conductuales asumidas por Oben Group permiten mitigar razonablemente los riesgos para la competencia ya enunciados; $y$,

Decimosexto: Que la aprobación del presente acuerdo extrajudicial no implica pronunciamiento sobre los hechos a que se refiere, ni impide, en caso alguno, que terceros que pudieren verse afectados por eventuales infracciones a la libre competencia derivadas de dichos hechos puedan presentar las acciones que en su concepto procedan. (Acuerdo Extrajudicial entre Fiscalía Nacional Económica, Oben Holding Group S.A.C, Bopp Chile S.A. y Pack Film Chile SpA., 2014)

Como se puede apreciar, la aprobación de un acuerdo extrajudicial se realiza sin que el Tribunal de Defensa de la Libre Competencia emita un pronunciamiento sobre el fondo, sino esencialmente provisional, como es propio de la protección jurídica que se obtiene a través de las medidas cautelares.

En cuanto al contenido de esta tutela, siguiendo la clásica explicación de Calamandrei (2017),

...las providencias cautelares tienen su inconfundible fisonomía procesal, que permite colocarlas en la sistemática del proceso como categorías por sí mismas, determinables a base de criterios que, aun no siendo los mismos sirven para distinguir las providencias de cognición de las de ejecución, no se transforman por eso de procesales en materiales. (p.137)

Como lo indica a reglón seguido el mismo autor:

...la definición de las providencias cautelares, ha de buscarse, más que a base de un criterio ontológico, a base de un criterio teleológico: no en la cualidad (declarativa o ejecutiva) de sus efectos, sino en el fin (anticipación de los efectos de la providencia principal), a que sus efectos están preordenados; ya que éstos aparecen desde su iniciación destinados a extinguirse en el momento en que puedan ceder el puesto o los efectos de la providencia cautelar. (Calamandrei, 2017, p. 137)

También siguiendo los criterios clásicos, con la aprobación de estos acuerdos por el Tribunal de Defensa de la Libre Competencia surge lo que la doctrina califica como de una cautela de tipo innovativa, como se sabe, en el plano teórico se distinguen básicamente dos manifestaciones de protección cautelar: a) las medidas cautelares conservativas, y b) las medidas cautelares innovativas. Esta división dogmática se debe a Carnelutti (1944), que propuso distinguir entre prevención conservativa y 
Los acuerdos extrajudiciales en materia de libre competencia como tutela...

prevención innovativa.

Las medidas cautelares innovativas, en descripción de Carnelutti (1944, pp. 249-251), se encaminan a producir una alteración del estado de hecho, que, de no mediar, comprometerían el resultado del proceso. Efectivamente, la cautela innovativa se caracteriza porque sin que exista sentencia firme sobre el fondo de una controversia, se ordena que se haga o se deje de hacer algo en sentido contrario al representado por la situación existente (Minvielle, 1985). En palabras de Peyrano (2009), este tipo de medidas se caracteriza por conformar:

...una diligencia precautoria excepcional que tiende a modificar el estado de hecho o de derecho existente antes de la petición de su dictado, medida que se traduce en la injerencia del tribunal en la esfera de libertad de los justiciables a través de la orden de que cese una actividad contraria a derecho o de que se retrotraigan las resultas consumadas de un proceder antijurídico. Dicha diligencia cautelar - a diferencia de la mayoría de las otras- no afecta la libre disposición de bienes, ni dispone que se mantenga el statu quo. Va más allá, ordenando -sin que concurra sentencia firme de mérito- que alguien haga o deje de hacer algo, en sentido contrario al representado por la situación existente. (p. 13)

En el caso de los acuerdos extrajudiciales, su finalidad cautelar permite proteger la libre competencia logrando los efectos propios de la cautela innovativa, al generar cambios en estados de hecho para prevenir o haciendo cesar conductas que pueden afectar al mercado. Lo anterior, se ha logrado a través de medidas tales como, restringir el derecho a la información, impedir que una sociedad competidora pueda elegir directores o ejecutivos o empleados de una empresa de su competidora (Acuerdo Extrajudicial entre FNE y Tianqi Lithium Corporation, 2018); imponiendo la renuncia a ejercer los derechos corporativos asociados a su participación minoritaria de una sociedad, que le permitirían influir en decisiones estratégicas otra empresa (Acuerdo extrajudicial entre FNE y Electrolux Chile S.A., 2015), entre otras soluciones de corte innovativo.

\section{Aspectos procesales de esta medida cautelar}

El sistema cautelar se explica tradicionalmente considerando tres elementos esenciales: el fumus boni iuris y el periculum in mora y la exigencia de una caución. El fumus boni iuris, es el juicio de verosimilitud acerca de la existencia del derecho que se reclama. El periculum in mora, por su parte, se refiere a la situación de peligro, cuya consumación se busca evitar mediante la concesión de la medida precautoria.

En el tema que nos ocupa, los elementos indicados se cumplen de diversa forma, según se trate de la intervención de la Fiscalía Nacional Económica o del Tribunal de Defensa de la Libre Competencia. A la primera, le compete la investigación 
de situaciones de riesgo para el buen funcionamiento del mercado, cuya consumación se busca evitar mediante la suscripción de los acuerdos extrajudiciales que negocia con los agentes económicos que han sido sometidos a una investigación administrativa.

El Tribunal de Defensa de la Libre Competencia, por su lado, debe controlar la concurrencia del parámetro legal previsto para aprobar o rechazar dicho acto cautelar, verificando que se hayan propuesto medidas que mejoren efectivamente las condiciones de competencia existentes en la situación de peligro.

Cuando la FNE concluye el acuerdo con el agente económico investigado, se debe someter su contenido al conocimiento del Tribunal de Defensa de la Libre Competencia, para que lo apruebe o rechace. Si la resolución es aprobatoria surge la protección cautelar preventiva y autónoma, que evita la consumación del peligro latente en el mercado. Sin esta autorización del Tribunal de Defensa de la Libre Competencia, no se cumple con la condición para que el acuerdo extrajudicial obtenga la eficacia jurídica indicada. Si el mencionado tribunal no le da su aprobación, la FNE deberá seguir adelante con su investigación, deduciendo el requerimiento si los antecedentes reunidos lo justifican.

En la práctica ratifica la naturaleza jurisdiccional de la medida cautelar, la inclusión de una cláusula de estilo que se incorporan al acuerdo, en virtud de la cual se establece que él queda sujeto a aprobación por parte del Tribunal de Defensa de la Libre Competencia, de conformidad a lo establecido en el artículo 39 letra ñ) del Decreto Ley, y que entrará en vigor sólo una vez que la resolución judicial que lo apruebe se encuentre firme y ejecutoriada ${ }^{5}$.

Desde el punto de vista teórico, conviene recordar que la doctrina ha diferenciado diversos grados de intensidad para aprobar o rechazar las medidas precautorias, distinguiendo rangos que van desde el control intenso a uno superficial o menos intenso, sobre esta distinción, ver Ramos Romeu (2006, pp. 429-432).

En la actual regulación, el parámetro cautelar que utiliza el Tribunal de Defensa de la Libre Competencia depende obviamente del asunto sometido a su aprobación, pero que se puede calificar que se trata de un control "menos intenso", pero no por ello protector del funcionamiento del mercado. Lo anterior, se desprende de las resoluciones aprobatorias que se han dictado en estos asuntos. A modo de ejemplo, ello costa en la resolución del Tribunal de Defensa de la Libre Competencia, de 4 de octubre de 2018, al declarar:

\footnotetext{
${ }^{5}$ Esto consta, a modo de ejemplo, en los autos caratulados Acuerdo Extrajudicial entre FNE y Tianqi Lithium Corporation (2018); en igual sentido, Acuerdo Extrajudicial propuesto por la FNE, Holchile y Caburga (2017); Acuerdo Extrajudicial entre Storbox S.A. y Iron Mountain Chile S.A. (2013).
} 
Noveno: Que, tal como se ha resuelto por la jurisprudencia en esta sede, el estudio de un acuerdo extrajudicial por este Tribunal tiene por objeto establecer si las medidas acordadas son suficientes y proporcionales para prevenir los eventuales riesgos para la libre competencia identificados por la FNE (v.gr. resoluciones de término en causas Rol $A E N^{\circ} 12-15$ y $\left.A E N^{\circ} 13-16\right) ;$

Décimo: Que, en este sentido y de acuerdo con los antecedentes que obran en el proceso, el análisis de los riesgos para la libre competencia que la FNE detectó en su investigación resulta adecuado, atendidas las características de los mercados concernidos y el alcance de la Operación. Por tanto, corresponde determinar si las medidas acordadas cumplen con el estándar indicado en el considerando anterior. (Acuerdo Extrajudicial entre FNE y Tianqi Lithium Corporation, 2018)

Sigue la pauta anterior la resolución del Tribunal de Defensa de la Libre Competencia, de 28 de enero de octubre de 2016, al aprobar el acuerdo extrajudicial surgido por los efectos de la Ley $\mathrm{N}^{\circ} 20.750$, que en el mercado de la televisión digital terrestre otorgaba a los concesionarios de alcance nacional en la banda VHF el derecho a conservar sus actuales concesiones analógicas $u$ optar por otras concesiones digitales en la banda UHF, señalando:

Decimocuarto: Que, atendido el breve plazo establecido por la ley para aprobar o rechazar un acuerdo extrajudicial y la inexistencia de una etapa procesal que permita recabar más antecedentes que los contenidos en el expediente de investigación de la FNE, el análisis de este Tribunal se limitará a establecer si las medidas acordadas por la Fiscalía con los Canales son suficientes y proporcionales para prevenir los eventuales riesgos para la libre competencia identificados por ese Servicio;

Decimoquinto: Que, en primer término, el acuerdo extrajudicial identifica riesgos de intercambios de información sensible entre competidores y de coordinaciones anticompetitivas entre ellos. Ese tipo de riesgos se encuentra presente, en mayor o menor medida, en toda clase de acuerdos o colaboraciones entre competidores. Sin embargo, la magnitud de los riesgos de intercambio de información y de coordinación se encuentra directamente vinculada con la naturaleza del acuerdo de cooperación analizado. En este sentido, cuando la cooperación entre competidores se restringe a aspectos técnicos -como en el caso del RIDA-, esta clase de riesgos tiene un alcance más acotado que en aquellos casos en los que involucre variables de producción o comercialización;

Decimosexto: Que en el acuerdo extrajudicial se contemplan, aunque de forma oblicua, las siguientes medidas conducentes a mitigar riesgos de coordinación e intercambio de información entre los Canales: (i) la prevención de que el acuerdo extrajudicial no importa una autorización para realizar actividades comerciales conjuntas (párrafo primero de la sección IV del acuerdo extrajudicial); y (ii) la regulación de las reuniones entre ejecutivos de los Canales, consistente en: (a) fijar previamente una tabla de temas a tratar, la que sólo podrá referirse a decisiones necesarias para el proyecto RIDA y sujetarse estrictamente a ella; (b) llevar acta de lo tratado en las reuniones que sea fir- 
mada por todos los asistentes; y (c) observar esas precauciones tanto en reuniones presenciales como no presenciales (número v. del título "Varios" del borrador de bases de licitación, contenido en el anexo VI del acuerdo extrajudicial);

Decimoséptimo: Que las medidas contempladas en el párrafo anterior, si bien son conducentes a mitigar los riesgos de coordinación y de intercambio de información sensible, no los eliminan por completo. En este sentido, sería conveniente que los Canales adopten, por su cuenta, otras medidas que sean propicias para hacerse cargo de estos riesgos, tales como la adopción de programas de cumplimiento (compliance) en libre competencia, la capacitación en materias de libre competencia a los ejecutivos que intervengan en el RIDA o que puedan participar en reuniones con competidores, $u$ otras semejantes (Acuerdo extrajudicial alcanzado entre la Fiscalía Nacional Económica y Televisión Nacional de Chile, Canal Dos S.A., Compañía Chilena de Televisión S.A., Red de Televisión Chilevisión S.A., Red Televisiva Megavisión S.A. y Canal 13 S.A, 2016)

Ratifica lo anterior, la jurisprudencia del Tribunal de Defensa de la Libre Competencia, cuando para aprobar estos acuerdos extrajudiciales invoca la cláusula prima facie o expresiones análogas, admitiendo con ello que su actuación se efectúa a partir de una realidad fáctica limitada. Recordemos que la locución latina prima facie quiere decir "... a primera vista o en principio, con lo que se da a entender la apariencia de un derecho o de una situación, pero sin que con ello se prejuzgue el asunto" (Ossorio, 2000, p. 795).

Una vez aprobado el acuerdo extrajudicial surge una situación procesal provisional, cuyo contenido está determinado por el tipo de medidas que hayan sido aprobadas por el Tribunal de Defensa de la Libre Competencia, para lograr actos positivos o negativos de los agentes económicos vinculados a este acto.

El estado jurídico cautelar autónomo generado a través de este instituto, debe cesar una vez que se cumple el fin de las medidas adoptadas o cambian las condiciones tenidas a la vista por el Tribunal de Defensa de la Libre Competencia para aprobarlo. En efecto, se debe resaltar que la protección cautelar que contiene un acuerdo extrajudicial se dicta con la cláusula rebus sic stantibus, en virtud de la cual sus efectos se mantienen mientras duren los supuestos que la autorizaron (Sobre esta regla; Martínez Velencoso y Orduña Moreno, 2017). Una vez que esa base desaparece, debe concluir esta forma de protección jurídica. En consecuencia, el FNE, el agente económico beneficiado con el acuerdo, o incluso terceros que sean titulares de un interés legítimo, pueden solicitar modificar, cesar o declarar extinta la protección cautelar surgida de la suscripción de un acuerdo extrajudicial, instando ante el Tribunal de Defensa de la Libre Competencia por el cambio que sea necesario introducir.

El carácter mutable del acuerdo, se aprecia por el hecho que la FNE haya previsto en varios casos recibir reportes periódicos o informaciones sobre el cumpli- 
miento de las medidas, sin perjuicio de la potestad de impetrar la petición de información general que permita comprobar el cumplimiento del acuerdo y las medidas de mitigación surgidas de la aprobación judicial del Tribunal de Defensa de la Libre Competencia. Ratifica lo anterior, la práctica de incluir también en estos actos una cláusula sobre modificación y renuncia, reconociendo competencia para tal evento al Tribunal de Defensa de la Libre Competencia, al señalar que cualquier modificación del acuerdo quedará sujeto a lo que oportunamente resuelva el Tribunal de Defensa de la Libre Competencia en el ejercicio de sus funciones ${ }^{6}$.

Por su parte, la naturaleza cautelar que hemos explicado no priva a estos acuerdos extrajudiciales de su carácter vinculante. El efecto imperativo está reconocido expresamente el art. 39 letra ñ) del Decreto Ley $N^{\circ} 211$, y debe ser explicado dentro de la cautela autónoma prevista en el sistema de protección de la defensa de la libre competencia, que permite imponer obligaciones a las partes que lo suscribieron, dejando a salvo los derechos los terceros (Normalmente esto se expone en los acuerdos expresamente, tal como consta, por ejemplo, en el aprobado por el Tribunal de Defensa de la Libre Competencia: Acuerdo Extrajudicial entre Fiscalía Nacional Económica, Oben Holding Group S.A.C, Bopp Chile S.A. y Pack Film Chile SpA., 2014). La circunstancia que no se haya resuelto una acción sobre el fondo no priva a estos actos de su poder coercitivo, que permite hacerlos cumplir a través de los medios previstos en este proceso especial que ampara el buen funcionamiento del sistema de mercado en nuestro país.

\section{El acuerdo extrajudicial y el equivalente jurisdiccional de la transacción}

Los acuerdos extrajudiciales que suscribe la Fiscalía Nacional Económica con los agentes económicos investigados conforman un instrumento singular, que se diferencia del contrato de transacción, definido en el art. 2446 del Código Civil (2000), aunque a primera vista podrían asimilarse (Arancibia Mattar, 2013, p. 480, niega el carácter de transacción). En efecto, este tipo de acuerdos extrajudiciales constituyen una expresión dentro de un género que se ha ido desarrollando en el ámbito del derecho para obtener la solución negociada de diverso tipo de conflictos, pero sin significar siempre lo mismo (Un estudio general de estos instrumentos en: Jequier Lehuedé, 2018; y Goldenberg Serrano, 2014).

La distinción más evidente, proviene del objeto sobre el que recae uno u otro. Como lo ha señalado la jurisprudencia del Tribunal de Defensa de la Libre Compe-

\footnotetext{
${ }^{6}$ Así consta en el número 63 del acuerdo presentado en los autos caratulados Acuerdo Extrajudicial entre FNE y Tianqi Lithium Corporation (2018). En igual sentido, en la cláusula séptima del Acuerdo Extrajudicial entre Storbox S.A. y Iron Mountain Chile S.A (2013); Acuerdo Extrajudicial propuesto por la FNE, Holchile y Caburga (2017, n. 92).
} 
tencia, los bienes protegidos por la normativa de libre competencia son de orden público y, como tales, indisponibles, sea por las partes, sea por la Fiscalía Nacional Económica. En cambio, el art. 2447 del Código Civil (2000) exige para la transacción la disponibilidad de los bienes que se transigen.

Desde otro punto de vista, los acuerdos extrajudiciales están al margen de los moldes clásicos. Se trata de una protección cautelar autónoma vinculada al ejercicio de potestades y competencias administrativas de la Fiscalía Nacional Económica.

\section{Conclusiones}

La institucionalidad de defensa de la libre competencia considera la posibilidad de suscribir acuerdos extrajudiciales, como una manifestación de la denominada tutela diferenciada para solucionar conflictos en ese ámbito, sin la necesidad de iniciar un proceso contencioso mediante el ejercicio de una acción.

Los acuerdos extrajudiciales que puede suscribir la Fiscalía Nacional Económica con el agente económico investigado administrativamente, provoca una serie de efectos que los separan de los institutos procesales clásicos, generando una medida de protección cautelar autónoma, prevista expresamente en la normativa del Decreto Ley No 211 (1973).

La jurisprudencia del Tribunal de Defensa de la Libre Competencia les presta su aprobación, pero previniendo que lo hace sin contar con información suficiente para pronunciarse definitivamente sobre las medidas mitigatorias propuestas. Esa modalidad ratifica que estamos frente a un acto de naturaleza cautelar.

En el caso de la regulación de los acuerdos extrajudiciales, surgen del ejercicio de la potestad administrativa prevista para la Fiscalía Nacional Económica, pero que configuran finalmente una manifestación de la tutela cautelar jurisdiccional, atendido que son conocidos y aprobados por el Tribunal de Defensa de la Libre Competencia.

El acuerdo extrajudicial aprobado por el Tribunal de Defensa de la Libre Competencia hace surgir una situación procesal provisional, para lograr actos positivos o negativos de los agentes económicos vinculados a este acto.

El estado jurídico cautelar autónomo generado surgido de los acuerdos, debe cesar una vez que se cumple el fin de las medidas adoptadas o cambian las condiciones tenidas a la vista por el Tribunal de Defensa de la Libre Competencia para aprobarlo. 
Los acuerdos extrajudiciales en materia de libre competencia como tutela...

\section{Referencias Bibliográficas}

Acuerdo extrajudicial alcanzado entre la Fiscalía Nacional Económica y Televisión Nacional de Chile, Canal Dos S.A., Compañía Chilena de Televisión S.A., Red de Televisión Chilevisión S.A., Red Televisiva Megavisión S.A. y Canal 13 S.A., Rol AE N 13-2016 (Tribunal de Defensa de la Libre Competencia 28 de enero de 2016) Recuperado de https://www.tdlc.cl/

Acuerdo extrajudicial entre la FNE e International Mainstream Renewable Power Limited, Rol AE No 15-2018. (Tribunal de Defensa de la Libre Competencia. 24 de mayo de 2018). Recuperado de https://www.tdlc.cl/

Acuerdo extrajudicial entre FNE, Storbox S.A. y Iron Mountain Chile S.A., Rol AE N62013 (Tribunal de Defensa de la Libre Competencia 09 de abril de 2013). Recuperado de https://www.tdlc.cl/

Acuerdo extrajudicial entre FNE y Holchile S.A. e Inversiones Caburga Ltda, Rol AE No 14-2017 (Tribunal de Defensa de la Libre Competencia 29 junio 2017). Recuperado de https://www.tdlc.cl/

Acuerdo extrajudicial entre FNE y Tianqi Lithium Corporation, Rol AE No 16-2018 (Tribunal de Defensa de la Libre Competencia 4 de octubre de 2018). Recuperado de https://www.tdlc.cl/

Acuerdo extrajudicial entre Fiscalía Nacional Económica, Oben Holding Group S.A.C, Bopp Chile S.A. y Pack Film Chile SpA., Rol AE No 10-2014 (Tribunal de Defensa de la Libre Competencia 6 de noviembre de 2014). Recuperado de https://www.tdlc.cl/

Acuerdo extrajudicial entre FNE y Electrolux Chile S.A., Rol AE No 12-2015 (Tribunal de Defensa de la Libre Competencia 16 de septiembre de 2015). Recuperado de https://www.tdlc.cl/

Aguirrezabal Grünstein, M. (2016). Las medidas cautelares innovativas en la nueva institucionalidad medioambiental. Revista de derecho (Coquimbo), 23(1), 23-49. doi: $10.4067 /$ s0718-97532016000100002

Aguirrezabal Grünstein, M. (2013). Algunas precisiones en torno a las medidas cautelares innovativas en el procedimiento por violencia intrafamiliar. Revista chilena de derecho privado, 21, 459-473. Recuperado de https://bit.ly/2ZE6zhT

Arancibia Mattar, J. (2013). Sobre el acuerdo extrajudicial de la Fiscalía Nacional Económica. En J. Arancibia Mattar, J. I. Martínez Estay y A. Romero Seguel (Coords.), Precedente, cosa juzgada y equivalentes jurisdiccionales en la litigación pública (pp. 477-500). Santiago: Abeledo Perrot. 
Ariza Colmenarejo, M. J. (2012). La acción de cesación como medio para la protección de consumidores y usuarios. Pamplona: Aranzadi.

Berizonce, R. O. (2009). Tutelas procesales diferenciadas. Buenos Aires: RubinzalCulzoni.

Bordalí Salamanca, A. (2001). Diversos significados de la tutela cautelar en el proceso civil. Revista de derecho (Valdivia), 12(2), 50-66. Recuperado de https://bit.ly/3jhGpsP

Bustamante con Román, Rol No 39406-2017 (Corte Suprema 26 de marzo de 2018). Recuperado de http://cl.microjuris.com id: MJJ53769

Calamandrei, P. (2017). Introducción al estudio sistemático de las providencias cautelares. Santiago: Olejnik.

Carrasco Delgado, N. (2012). Análisis económico de las medidas cautelares civiles. Santiago: Abeledo Perrot.

Carnelutti, F. (1944). Sistema de derecho procesal civil (Vol. 1) (N. Alcalá-Zamora y CastiIlo y S. Sentís Melendo, Trads.). Buenos Aires: Uteha.

Código Civil. Diario Oficial de la República de Chile, Santiago, Chile, 30 de mayo de 2000. Recuperado de http://bcn.cl/1uqm8

Decreto con Fuerza de Ley $\mathrm{N}^{\circ} 1$. Fija el texto refundido, coordinado y sistematizado del Decreto Ley N²11, de 1973. Diario Oficial de la República de Chile, Santiago, Chile, 07 de marzo de 2005. Recuperado de http://bcn.cl/2ewvo

Decreto Ley 211. Fija normas para la defensa de la libre competencia. Diario Oficial de la República de Chile, Santiago, Chile, 22 de diciembre de 1973. Recuperado de http://bcn.cl/2ewvh

Etcom S. A. con Telefónica Móviles Chile S.A, Rol № 34045-2016 (Corte Suprema 14 de septiembre de 2017). Recuperado de http://cl.microjuris.com id: MJJ51427

Goldenberg Serrano, J. L. (2014). Los acuerdos extrajudiciales desde la visión privatista del derecho concursal. Revista de derecho (Valparaíso), (42), 187-223. doi: $10.4067 /$ s0718-68512014000100006

Historia de la Ley $N^{\circ}$ 20.361. Modifica el Decreto con fuerza de Ley №1 del Ministerio de Economía, Fomento y Reconstrucción, de 2005, sobre Tribunal de Defensa de la Libre Competencia. Biblioteca del Congreso Nacional de Chile, 4 de Mayo de 2018. Recuperado de http://s.bcn.cl/21hu3

Jequier Lehuedé, E. (2018). La ejecución del acuerdo de mediación en asuntos civiles y comerciales. Una revisión impostergable. Revista de derecho (Valdivia), 31(2), 71-93. doi: $10.4067 /$ s0718-09502018000200071 
Los acuerdos extrajudiciales en materia de libre competencia como tutela...

Ley N $\mathrm{N}^{\circ}$ 1.552. Código de procedimiento civil. Diario Oficial de la República de Chile, Santiago, Chile, 30 de agosto de 1902. Recuperado de http://bcn.cl/1uw3q

Marín González, C. J. (2016). Tratado de las medidas cautelares: Doctrina, jurisprudencia, antecedentes históricos y derecho comparado (2a ed.). Santiago: Jurídica de Chile.

Martínez Velencoso, M. L. y Orduña Moreno, J. F. (2017). La moderna configuración de la cláusula "Rebus Sic Stantibus". Tratamiento jurisprudencial y doctrinal de la figura (2a ed.). Madrid: Civitas.

Minvielle, B. (1985). La problemática de la medida cautelar innovativa. Revista Uruguaya de derecho procesal, (2), 362.

Ossorio, M. (2000). Diccionario de ciencias jurídicas, políticas y sociales (27a ed.). Buenos Aires : Heliasta.

Pardow, D. G. (2015). El desempeño en juicio de la FNE: ¿es realmente un mejor litigante que los demandantes privados? Revista de derecho (Coquimbo), 22(2), 419-451. doi:10.4067/s0718-97532015000200014

Peyrano, J. (2009). La palpitante actualidad de la medida cautelar innovativa. En su Medida innovativa. Buenos Aires: Rubinzal-Culzoni.

Pérez Ragone, A. (2000) Concepto estructural y funcional de la tutela anticipativa. Revista de derecho procesal, (1), 157-213.

Proto Pisani, A. (2014). La tutela jurisdiccional (G. Priori y C. Delgado, Trads.). Lima: Palestra.

Ramos Romeu, F. (2006). Las medidas cautelares civiles. Un análisis jurídico-económico. Barcelona: Atelier.

Reyes Cid, C. (15 Noviembre 2018). Los acuerdos extrajudiciales. Soluciones alternativas en libre competencia. El Mercurio. Recuperado de https://bit.ly/2WCNLNS

Rivas Sánchez, V. (27 de Noviembre de 2018). Los acuerdos extrajudiciales como una alternativa eficiente a la judicialización en materia de libre competencia. Recuperado de https://bit.ly/39bSOKr

Romero Guzmán, J. J. (2014). Ejecución y cumplimiento de un marco normativo de libre competencia. Influencias y opciones de diseño. Santiago: Thomson Reuters.

Romero Seguel, A. (2017). Curso de derecho procesal civil (3a ed., Vol. 1). Santiago: Legal Publishing.

Rojas, J. A. (2006). Los sistemas cautelares. En A. M. Morello (Ed.), Medidas cautelares (pp. 15-37). Buenos Aires: La Ley. 
Valdés Prieto, D. (2006). Libre competencia y monopolio. Santiago: Editorial jurídica de Chile.

Valdés Prieto, D. (2010). Acuerdos extrajudiciales antimonopólicos y principio de eficiencia. Revista de derecho público, (73), 221-235. doi:10.5354/0719-5249.2010.35667

Velozo Alcaide, J. y González Delpiano, D. (2011). Reflexiones en torno a algunas de las facultades extrajurisdiccionales del tribunal de defensa de la libre competencia. En Tribunal de Defensa de la Libre Competencia (Ed.), La libre competencia en el Chile del Bicentenario (pp. 21-71). Santiago: Thomson Reuters.

Órbenes Órbenes, Sergio y otro con Meza Tapia, Enrique, Rol № 2659-2010 (Corte Suprema 31 de agosto de 2011). Recuperado de http://cl.microjuris.com id: MJJ29059

Servicio Nacional del Consumidor con Ticketmaster Chile S.A, Rol No 62158-2016 (Corte Suprema 9 de abril de 2018). Recuperado de http://cl.microjuris.com id: MJJ54462

\section{Para citar este artículo bajo Norma APA 6a ed.}

Romero Seguel, A. (2020). Los acuerdos extrajudiciales en materia de libre competencia como tutela cautelar autónoma. Revista de Derecho (Coquimbo. En línea), 27, e4381, https://doi.org/10.22199/issn.0718-9753-2020-0010

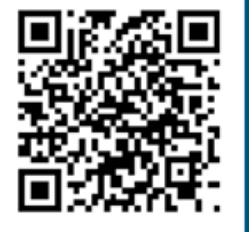

DOI

\section{(cc) BY}

Este es un artículo de acceso abierto, bajo licencia Creative Commons BY 4.0. 